Canadian

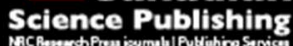

Applied Physiology, Nutrition, and Metabolism Physiologie appliquée, nutrition et métabolisme

\title{
Effectiveness of a school-based program focusing on diet and health habits taught through physical exercise
}

\begin{tabular}{|r|l|}
\hline Journal: & Applied Physiology, Nutrition, and Metabolism \\
\hline Manuscript ID & apnm-2017-0348.R2 \\
\hline Manuscript Type: & Article \\
\hline Date Submitted by the Author: & $29-$ Oct-2017 \\
\hline Complete List of Authors: & $\begin{array}{l}\text { Pablos, Ana; Universidad Católica de Valencia San Vicente Mártir, Faculty } \\
\text { of Physical Activity and Sport Sciences } \\
\text { Nebot, Vicente; Universidad Católica de Valencia San Vicente Mártir, } \\
\text { Faculty of Physical Activity and Sport Sciences } \\
\text { Vañó-Vicent, Vicente; Universidad Católica de Valencia San Vicente Mártir, } \\
\text { Doctoral School } \\
\text { Ceca, Diego; Universidad Católica de Valencia San Vicente Mártir, Doctoral } \\
\text { School } \\
\text { Elvira, Laura; Universidad Católica de Valencia San Vicente Mártir, Physical } \\
\text { Activity and Sports }\end{array}$ \\
\hline Is the invited manuscript for \\
consideration in Special \\
Issue? :
\end{tabular}


Effectiveness of a school-based program focusing on diet and health habits taught through physical exercise

Ana Pablos, Vicente Nebot, Vicente Vañó-Vicent, Diego Ceca, and Laura Elvira

A. Pablos. Faculty of Physical Activity and Sport Sciences, Universidad Católica de Valencia "San Vicente Mártir", C/ Ramiro de Maeztu, 14, 46900, Torrent, Valencia, Spain. Tel. 0034963637412,e-mail: ana.pablos@ucv.es (Corresponding autor).

V. Nebot and L. Elvira. Faculty of Physical Activity and Sport Sciences, Universidad Católica de Valencia "San Vicente Mártir"

V. Vañó and D. Ceca. Doctoral School, "Universidad Católica de Valencia "San Vicente Mártir", Valencia, Spain, 


\begin{abstract}
The global rate of obesity in childhood is becoming an epidemic and many authors have established a significant association between childhood obesity and overweight in adulthood. It is therefore necessary to seek effective strategies to reduce these levels of obesity. The aim of this study was to evaluate the impact of the Healthy Habits Program (HHP). The participants were 158 children from the 5 th and 6th grades (Intervention Group [IG] n=82, Control Group [CG] n=76). The HHP is a school-based physical activity program focusing on promoting a healthy lifestyle. It lasted for 8 months, and measurements were taken at the beginning and end of the program. Physiological variables (total cholesterol, triglycerides, blood glucose, blood pressure and VO2max), anthropometric variables (BMI) and behavioral variables (breakfast, quality of diet, meal frequency, physical activity, sedentary behavior, sleep and perceived health) were evaluated. Repeated measures analysis of variance showed significant improvements $(p<.05)$ after the intervention for the IG in triglycerides, blood glucose and VO2max. Significant improvements were also observed in breakfast habits and quality of diet. Lastly, a significant improvement in prevalence of normal levels was observed for total cholesterol, blood pressure and BMI. It can therefore be stated that the HHP is an innovative and useful school-based program that can help to improve diet and health in childhood.
\end{abstract}

Key words: obesity, health promotion, exercise, health habits, nutrition 


\section{Résumé}

Le taux global d'obésité dans l'enfance devient une épidémie et de nombreux auteurs ont établi une association significative entre l'obésité infantile et le surpoids à l'âge adulte. Il est donc nécessaire de rechercher des stratégies efficaces pour réduire ces niveaux d'obésité. Le but de cette étude était d'évaluer l'impact du programme Healthy Habits (HHP). Les participants étaient 158 enfants de la 5ème et 6ème années (Groupe d'Intervention [IG] n = 82, Groupe de Contrôle [CG] $\mathrm{n}=76$ ). Le programme HHP est un programme d'activité physique en milieu scolaire axé sur la promotion d'un mode de vie sain. Il a duré 8 mois et les mesures ont été prises au début et à la fin du programme. Les variables physiologiques (cholestérol total, triglycérides, glycémie, tension artérielle et VO2max), les variables anthropométriques (indice de masse corporelle) et comportementales (petit déjeuner, qualité de l'alimentation, fréquence des repas, activité physique, comportement sédentaire, sommeil et santé perçue) ont été évaluées. Des mesures répétées de la variance ont montré des améliorations significatives $(\mathrm{p}<0,05)$ après l'intervention pour l'IG dans les triglycérides, la glycémie et VO2max. Des améliorations significatives ont également été observées dans les habitudes de petit déjeuner et la qualité de l'alimentation. Enfin, une amélioration significative de la prévalence des taux normaux a été observée pour le cholestérol total, la pression artérielle et l'indice de masse corporelle. On peut donc affirmer que le programme HHP est un programme scolaire novateur et utile qui peut aider à améliorer l'alimentation et la santé durant l'enfance.

Mots-clés: obésité, promotion de la santé, exercice, habitudes de santé, nutrition 


\section{Introduction}

Recently, there has been an upward trend in the global rate of obesity in childhood and adolescence, which is becoming an epidemic (Ng et al. 2014, Morgen and Sørensen 2014). In addition, one scientific review highlights the significant association between childhood obesity and overweight in adulthood (Brisbois et al. 2012). Despite the strategies promoted by the World Health Organization (WHO) and by some countries to prevent overweight and obesity, there is little evidence that this worldwide epidemic is slowing down or has even plateaued (Llargués et al. 2009, Sánchez-Cruz et al. 2013).

We therefore suggest that strategies to prevent this disease should begin in childhood. It is essential to promote programs to teach and monitor healthier habits in children in order to prevent the development of various chronic diseases that have recently been related to overweight in adulthood (Tam et al. 2014). These programs could also help to curb the rising economic costs of inactivity (International Sport and Culture Association 2015).

The age group covered by this study is 10 to 12 years. During this period of life children go through rapid physical and psychosocial changes, as well as gaining more autonomy and decision-making power regarding health behaviors (Currie et al. 2012). Moreover, due to the greater brain plasticity that occurs as a result of changes in the limbic system, increased risktaking behavior is seen between the ages of 10 and 15 (Steinberg et al. 2008, Chorlian et al. 2013). This is because this period is characterized by relatively higher sensation seeking in the context of relatively lower impulse control; for this reason, it is essential to monitor the main health-related life habits, such as physical activity, screen leisure time, sleep time or consumption of unhealthy foods.

It is important to prevent this risk-taking behavior because patterns initiated in childhood or adolescence are strongly carried forward into adult life. In fact, of the ten leading risk factors for global Disability Adjusted Life Years (DALYs) identified in the 2010 Global Burden of 
Disease study, three are strongly determined in childhood, namely low fruit consumption, high body mass index, and physical inactivity (Institute for Health Metrics and Evaluation 2013).

However, an intervention in students of these ages should also be seen as an opportunity, because this greater brain plasticity also makes it a more favorable age at which to change their behavior (Tamnes et al. 2010, Chorlian et al. 2013).

Therefore, using a school-based intervention to promote a healthy lifestyle is very important in preventing risk-taking behaviors in school children. These interventions have shown immediate positive effects on health (Kriemler et al. 2011). With this aim, the purpose of this study was to evaluate the impact of the Healthy Habits Program (HHP). This is an innovative program that uses themed physical games to convey and modify health-related behaviors in line with the recommendations (Pérez-Rodrigo and Aranceta 2001, Silveira et al. 2011, Aranceta et al. 2015). It takes the form of an extracurricular activity that seeks to make prevention the best strategy in the fight against obesity. Its purpose is to bring health and education together within the school setting, with the involvement of the family, in order to achieve healthy lifestyle habits in the short and long term.

\section{Method}

\section{Participants}

Data were obtained from 158 students from 4 Spanish primary schools in Eastern Spain (Valencian Community, Spain). All the schools that took part in the study were public (government-funded) schools in urban areas. They were categorized as being of middle socioeconomic status, determined using the PISA index of economic, social and cultural status. The inclusion criteria involved (1) being in the 5th or 6th grade, and (2) not being enrolled in any other research study. 
The students were assigned to the control group ( $\mathrm{CG} ; \mathrm{n}=76)$ or the intervention group (IG; $\mathrm{n}=82$ ) according to the school they attended in order to avoid contamination. Each school was designated as a control or intervention group using 4 opaque envelopes containing the assigned treatment, which was handled by someone who was not involved in the study. The IG participated in the intervention program over 8 months. The CG continued with their daily activities without participating in the healthy habits program.

The study was conducted in accordance with the World Medical Association's Declaration of Helsinki for biomedical research and was approved by the Ethics Committee of the University of Valencia, Spain (H1437458363179). The children participated in the study voluntarily and written informed consent was obtained from their parents or guardians.

\section{Anthropometric variables}

Body weight $(\mathrm{BW})$ was measured to the nearest $0.01 \mathrm{~kg}$ and body height $(\mathrm{BH})$ was measured to the nearest $0.1 \mathrm{~cm}$ using a Seca714 scale (Seca Vogel \& Halke $\mathrm{GmbH} \&$ Co. KG, Hamburg, Germany) with a built-in height rod with 1-mm accuracy (range 60-200 cm). Body mass index (BMI: $\mathrm{kg} / \mathrm{m} 2)$ was calculated as BW $(\mathrm{kg})$ divided by height squared $\left(\mathrm{m}^{2}\right)$. Normal weight, overweight and obesity were defined according to the reference values for BMI in children based on age and sex (de Onis et al. 2007). The protocols followed were those established by the International Society for Advancement of Kinanthropometry (ISAK) (Stewart and Marfell-Jones 2006) and all the data were recorded by a qualified professional (ISAK Level I).

\section{Physiological variables.}

A blood sample was collected from a finger prick in a heparinized hematocrit tube following overnight fasting for at least 10 hours. Blood glucose (BG), total cholesterol (TC) and 
triglycerides (TG) were measured using validated portable Accutrend automated analyzers (Accutrend GCT Systems, Roche, Germany), which allow spectrophotometric analysis of whole blood without prior processing. The intra-assay coefficients of variation for BG, TC and TG were $4.6 \%, 3.7 \%$ and $3.4 \%$, respectively.

The results obtained for TC and TG were also recoded according to the percentiles defined in the lipid profile of the Spanish population (DRECE study) (Gómez-Gerique et al., 1999), and were classified as normal, high $(\geq p 90)$ and very high $(\geq$ p95). For BG, normal values were classified as $<100 \mathrm{mg} / \mathrm{dl}$, high between 100 and $125 \mathrm{mg} / \mathrm{dl}$, and very high as $\geq 126 \mathrm{mg} / \mathrm{dl}$ (American Diabetes Association 2015).

Blood pressure was measured using a digital sphygmomanometer (Omron M6 Comfort, Omron Healthcare, Kyoto, Japan) with appropriate cuff sizes. The children were seated for at least 10 minutes before their blood pressure was measured (Systolic Blood Pressure (SBP), Diastolic Blood Pressure (DBP)). Four categories were used to calculate the prevalence, taking into account the blood pressure percentiles according to age, sex and height: normal (SBP and DBP $<$ p90), pre-hypertension (SBP and/or DBP $\geq$ p90 but $<$ p95), stage 1 hypertension (SBP and/or DBP $\geq$ p95 and $<$ p99 $+5 \mathrm{mmHg}$ ), stage 2 hypertension (SBP and/or DBP $\geq$ p99 + 5 mmHg (de la Cerda and Herrero 2014).

The Cardiovascular Fitness Indicator was assessed using 1 item of the Eurofit physical fitness test battery. The selected item was the 20 meter shuttle run test (Léger and Gadoury 1989). This is an indirect incremental multistage field test over a distance of 20 meters to exhaustion using the pace set by a CD emitting beep signals at preset intervals. The initial speed was set at $8.5 \mathrm{~km} / \mathrm{h}$ for the first minute and was increased by $0.5 \mathrm{~km} / \mathrm{h}$ each subsequent minute. The result of this test was used to determine the $\mathrm{VO}_{2} \max$. Trained researchers administered the tests following a standardized protocol to ensure it was administered consistently. This test is 
an optimal cardiovascular fitness indicator for children and adolescents (Castro-Piñero et al. 2010).

\section{Health habit variables}

All of the participants were asked to fill out the Inventory of Healthy Habits (IHH) (Nebot et al. 2015a, 2015b). It is a questionnaire focusing on their lifestyle and eating habits. This inventory comprises a first part consisting of 27 items that record eating habits and a second part that records physical activity, sleep, sedentary habits and perceived health habits. This information is detailed in two previous articles by the research team (Nebot et al. 2015a, 2015b). The students taking part in the study completed the questionnaire in the presence of an assessor and always at the same time of day.

\section{Objective assessment of physical activity level during the program}

On each program activity day, two children were selected and an activity monitor (GT3X+, ActiGraph LLC, Pensacola, FL, USA) was attached to their hip with an elastic band. Different children were selected at each session. This measurement showed us the intensity of the session. The intensity domains used were sedentary (0-99 counts), light (100-1999), moderate (2000-4999) and vigorous (5000 - $-_{\infty}$ ) according to the latest update from ActiGraph LLC, Pensacola, FL, USA

\section{Intervention Procedure}

The HHP took place at two public schools in the Valencian Community in the form of a free extracurricular activity. It lasted for 8 months and was carried out by the IG in the form of sessions twice a week lasting for a total of 150 minutes per week. The sessions were given before lunch and began with a brief 10-minute talk about some of the healthy habits in 
question, such as diet, physical activity, sleep and hygiene. This was followed by a physical exercise session consisting of a 15-minute warm-up using games relating to the topic of the initial talk (themed games). The main part lasted for 40 minutes and used themed games for the first 22 sessions and modified sports for the rest of the sessions, which provided the motivational ingredient without restrictive rules or technical demands that could exclude less able students. Lastly, there was a 10-minute calming down section involving another themed game. All the sessions were led by the same specifically-trained teacher. The physical activities gradually increased in intensity and duration throughout the intervention. The intensity level of the activities was intended to be moderate to high, and the mean time spent at each activity level was $16.2 \%$ sedentary, $20.8 \%$ light, $38.3 \%$ moderate and $24.6 \%$ vigorous. Moreover, the following pedagogical premises were taken into account when designing the practical sessions: fun, inclusion and cooperation, and safety.

At the end of the session each student was given a worksheet designed by the research team to complete at home (p.e. Supplementary figure S1). The purpose of the worksheets was to reinforce the topic explored during the session. These worksheets had to be signed each week by the parents or guardians of the students participating in the program and they served as teaching materials for students and parents and as a link between parents and their children to support and stimulate lifestyle changes. These materials consisted of 29 worksheets, organized into 6 topics: 1) Why do we eat? 2) What and when should we eat? 3) Mealtimes 4) Doing exercise 5) Sleep duration 6) Hygienic habits. The topic explored in each session can be seen in the Supplementary table S1.

The program was also accompanied by three 45 -minute talks for parents and teachers about healthy habits for school children. They were held at the beginning of the school year and halfway through the year, and the topics covered were: Healthy habits and excess weight in children; Eating habits in school children; Diet and physical activity in children. 
The measurements were taken at the start of the program (baseline) and after the intervention ( 8 months). All the measurements were taken at the same time of day and at a similar temperature. Physiological and anthropometric variables were measured between 9 and 10 AM, after overnight fasting. The other measurements were taken between 10:30 and 12:30 on different days, two days apart.

\section{Statistical Analysis}

A descriptive analysis was used to determine the frequency distribution and measures of central tendency and dispersion (mean and standard deviation) between CG and IG, and at baseline vs. 8-months. The participants' characteristics were compared by group using an independent samples $t$ test or a chi-square test. For outcome measures, the changes from baseline to 8 months were compared for CG and IG using 2 (group) x 2 (time) repeated measures ANOVA with 95\% confidence intervals $(p<.05)$. The Bonferroni correction and post-hoc pairwise comparisons were used. McNemar's test was applied for the analyses of prevalence by levels and by time (baseline vs. 8 months) for the following variables: cholesterol, triglycerides, glucose, blood pressure and BMI. All statistical analyses were performed using SPSS version 22.0 statistical software (IBM Corp, Chicago, IL, USA).

\section{Results}

Of the 210 children enrolled, 190 children agreed to participate in the study $(\mathrm{CG}=90$; $\mathrm{IG}=100$ ). Thirty children were excluded because of missing administrative data or absence from school when the measurements were taken. Complete data were collected for 158 of the 190 children.

The demographics of the adolescents are shown in Table 1. 


\section{Anthropometric and Physiological Variables}

Anthropometric and physiological results after 8 months of intervention are reported in Table

2. It can be seen that significant improvements were obtained in the IG for triglycerides, blood glucose and VO2max.

Table 3 shows the prevalence for the biochemical variables, blood pressure and BMI according to level; significant improvements are observed in the IG with regard to triglycerides, blood pressure and BMI.

\section{Health Habit Variables}

After the intervention significant differences were observed in terms of eating a more complete breakfast and quality of diet, with better results in the group that participated in the intervention (Table 4).

\section{Discussion}

The purpose of the HHP is to improve children's health by seeking the most effective strategy against excess weight, which, according to Cordero et al. (2014), consists of combining physical activity with a better diet. However, this is an innovative program because it harnesses physical activity and uses themed physical games to connect with school children with the clear aim of teaching them about the need to improve their diet and health habits in order to make them healthier both now and in the future. In addition, the program has been carried out in the school setting to create a healthy environment involving teachers and friends, since adolescents are heavily influenced by their friends. This was demonstrated in a systematic review, in which it was noted that friends' dietary behavior can be an important and modifiable determinant of unhealthy food consumption in children (Sawka et al. 2015). 
We can therefore improve dietary behaviors through social support strategies that help the child make appropriate choices now and in the future.

Despite the importance of childhood and adolescence in people's future adult life, the health of adolescents and children is not addressed by public policies (Guzman 2012). In Spain, the overweight rate between the ages of 8 and 13 is approximately 45\% (Sánchez-Cruz et al. 2013). It is therefore necessary to develop programs like this one that focus on creating healthy environments based on physical exercise and education regarding healthy habits as key elements for preventing and treating excess weight at early ages.

As expected (Alberga et al. 2012), eating habits deteriorated in the CG, while these habits improved in those participating in the HHP. As regards breakfast, significant changes of almost 2 points were observed after the intervention in the IG, who had a fuller breakfast. A "full breakfast" refers to eating a healthy breakfast consisting of a variety of foods, especially high-fiber and nutrient-rich whole grains, fruit, and dairy products. This change achieved after the intervention is particularly significant because evidence suggests that eating breakfast generally has positive effects on cognitive performance in comparison with missing breakfast (Hoyland, Dye \& Lawton, 2009). Furthermore, a systematic review (Szajewska and Ruszczynski 2010) reported that overweight or obese children tend to have breakfast less frequently than normal-weight children, so eating breakfast is associated with a reduction in BMI in children and adolescents in Europe, probably due to a more even distribution of energy intake across meals throughout the day (Dubois et al. 2009).

In terms of the results, it can also be seen that after the intervention there is an improvement of almost 5 points in the quality of the different foods eaten throughout the day in the IG compared with the CG. This involves a higher intake of fruit and vegetables and a lower intake of sugary drinks, sweets and fast food. This change could be very important, as it has been seen that diets containing a variety of vegetables and fruit appear to decrease the risk of 
cancer and cardiovascular disease (Pomerleau et al. 2006), and diets containing optimal amounts of dairy products and/or calcium provide essential nutrients for bone growth and other health benefits (Rice et al. 2013), including the potential for improved weight regulation (Louie et al. 2011).

Along the same lines as our study, intervention studies such as the one conducted by Drapeau et al. (2016) show that this type of intervention in schools can improve children's consumption of healthy foods, but it is necessary to carry out multicomponent programs like ours to ensure a significant long-term impact on healthy behaviors.

As regards physical activity, after the intervention an increase of 15.71 minutes was observed in the IG with respect to the CG, although this is not enough to show significant differences between the two groups. In spite of this, it was observed that the level decreased in the CG, as described by McVeigh and Meiring (2014), who stated that physical activity decreases as the school year goes on. On the other hand, in the IG the amount of physical activity increased during the school year, reaching 80 minutes/day of physical activity after the program, thus exceeding the minimum recommended by the World Health Organization (2010). This is extremely important if one considers the large amount of evidence about doing regular physical activity within the recommended parameters and its positive impact on individual health (Fiuza-Luces et al. 2013, Pedersen and Saltin 2015), public health services (Lee et al. 2012), the economy (International Sport and Culture Association 2015) and quality of life in general.

Concerning sleep duration, short duration of sleep has been associated with a $45 \%$ increased risk of developing obesity (Li et al. 2017). Wu et al. (2015) showed odds ratios of overweight increasing as sleep duration decreased ( $<5.0$ hours/day, 5.0-6.9 hours/day, and 7.08.9 hours/day compared with students sleeping $\geq 9.0$ hours/day). This may be due to the relationship between short duration of sleep and decreased leptin levels and increased ghrelin 
levels, because this has been associated with increased hunger and appetite, which may affect the increase in BMI (Taheri et al. 2004).

In our case, the mean number of hours of sleep obtained in this study was more than 9 hours per night, which could be within the "optimal zone" proposed by Wu et al. (2015). Outside this "optimal zone" harmful effects of sleeping may disturb energy balance. Therefore, since the results are within what are considered to be correct values, no significant changes were found after applying the program, either between or within groups.

Regarding sedentary behavior, no significant changes were observed between groups after the intervention. Moreover, in both the first and the second measurement the students spent at least 2 hours per day on sedentary activities, meaning that the goal of less than 2 hours of total sedentary time per day was not achieved.

If we compare the number of hours of sedentary activity with other studies using self-report questionnaires in children of a similar age, Busto et al. (2006) obtained a total of 3.42 hours/day of sedentary time, which is considerably more than our data. In short, despite having managed to increase the number of hours of physical activity in the IG, there was no significant improvement in sedentary behavior, thus showing that this is a habit that is difficult to change in more developed societies, where the use of technology is becoming increasingly ingrained. It is therefore necessary for governments to seek ways to change this behavior because a 2012 analysis concluded that, at a global level, the proportion of total deaths owing to physical inactivity stands at $9 \%$ (Lee et al. 2012).

As regards self-perceived health index, no significant differences were observed between the groups after the program. However, the improvement obtained in the IG is slightly greater (.07 points), which may be due to the increase in physical activity (Gourlan et al. 2011). This could lead to positive experiences with physical education in schools (Jerdén et al. 2011). It 
should also be taken into account that the emotional, family-oriented, fun atmosphere of the program could be influencing the children's health perception.

With regard to $\mathrm{VO}_{2} \mathrm{max}$, significant differences were observed between the groups after the intervention. We consider this finding to be extremely important because the Shuttle Run Test is one of the most widely used tests in children and there is consensus that a higher $\mathrm{VO}_{2} \mathrm{max}$ in this test correlates with a better anthropometric and metabolic-lipid profile, both in childhood/adolescence and at future ages (Gálvez et al. 2014; García-Artero et al. 2007; Ruiz et al. 2016; Ruiz et al. 2009). These data are logically associated with the increase in physical activity in the IG.

The changes in $\mathrm{VO}_{2}$ max correspond to the values in the biochemical analyses, where a decrease in total cholesterol and triglyceride values was observed in the IG in relation to the CG after the program. Despite this, significant differences between the groups were only observed in the triglyceride values, although significance was almost reached in the total cholesterol values $(P=.087)$. With regard to the glucose parameters, lower values were obtained in the IG after the intervention $(-5.12 \mathrm{mg} / \mathrm{dl})$, but the mean levels were within normal ranges for these ages, except for $3.9 \%$ of $\mathrm{CG}$ children, who had high levels in the second measurement. This is the reason why significant differences were found between groups after the intervention.

The importance of our biochemical results should be stressed, because school interventions do not usually substantially improve lipoprotein levels, as in programs such as MOVIE or ICAPS (Mura et al. 2015). Our results are more similar to those reported by Luo et al. (2013), with a population of 216 obese children aged between 11 and 13 years. In their case the participants undertook a 6-week program in which they received a hypocaloric diet and did two 1.5 -hour sessions of physical activity per day for 6 days. After the program significant improvements were obtained in body weight, body mass index, waist circumference, body fat percentage, 
blood pressure, serum cholesterol and triglycerides, and the only non-significant physiological variable was fasting blood glucose.

However, we believe it is essential for programs to focus on making the child or adolescent a more active person and modifying their eating habits and making them healthier, because otherwise there is no significant effect on lipid profile parameters. This is the case of the study by Ardoy et al. (2013), which focuses only on increasing the number of hours of physical education per week.

Considering that obesity is closely related to cardiovascular disease (CVD) and an estimated $80 \%$ of children and adolescents with obesity will continue to be obese in adulthood because it is so difficult to treat (Brisbois et al. 2012), it is very encouraging to have been able to significantly reduce the prevalence of obesity in the IG and reduce the prevalence of children with type 2 hypertension and very high triglyceride levels. This shows the medium-term effectiveness of the program.

With regard to BMI, there was an increase of $0.57 \mathrm{~kg} / \mathrm{m}^{2}$ in the $\mathrm{IG}$ with respect to the CG after the intervention. This is in line with the results obtained in the meta-analyses by Dobbins et al. (2013) and Lavelle et al. (2012), where it is argued that school-based physical activity programs have no effect or, at best, a small effect on reducing BMI. This is because of the effect of physical development that takes place in school children of the ages being studied. However, if we analyze why this happened, it can be seen that the BMI increased significantly in the CG, as expected, while the participants in the IG managed to maintain their BMI. In fact, it has been stated that interventions are unlikely to have a significant effect on the increasing prevalence of childhood obesity, but we show that with this kind of program, obesity rates can decrease significantly $(p=.004)$. Specifically, the levels of obesity in the IG decreased by $9.9 \%$, which involved a $6.1 \%$ increase in overweight levels and a $3.7 \%$ increase in normal values. 
The present study has some limitations that should be considered, such as the design. Some schools were selected as the CG and others were chosen as the IG in order to prevent contamination bias, because if the same school had some students in the CG and others in the IG, this could have influenced the results in the CG.

Regarding the effects of the intervention, only two measurements were made in order to avoid wasting time during the sessions. Other studies describe better effects for interventions that are shorter than 6 months (Gourlan et al. 2011). Although we believe that the length of our program is ideal and that it could even be extended to cover several academic years, it would have been interesting to perform an intermediate measurement to verify whether there is a loss of these effects over time and even to perform a post- 6 month measurement to see whether the effects are maintained in the long term.

Another possible limitation involves the use of a questionnaire to record the health habit variables. Despite being self-administered, it is a short, simple questionnaire with good reliability in this age group. Furthermore, it can be administered to a large group in the presence of one supervisor, making it viable both economically and in terms of the resources required.

In conclusion, this study has shown the effectiveness of an innovative program for children aged 10-12 years. The IG experienced an improvement in eating habits and physical activity, as well as in their BMI, cardiovascular fitness indicator and total cholesterol, triglyceride and glucose levels. This shows that healthy lifestyle habits in adolescents can be controlled and improved, even in a relatively short period of time, despite this being a stage of life that is characterized by major changes, progressive independence and increased risk-taking.

It is essential to implement programs such as the one proposed in this article, as it is necessary to reduce the high rates of obesity. To achieve this, educators and health agents must join 
forces to combat unhealthy lifestyle habits, acknowledging that good health should not be an end in itself, but a consequence of an appropriate lifestyle.

\section{Conflicts of interest}

The authors report no conflicts of interest associated with this manuscript.

\section{Acknowledgements}

The authors would like to thank all of the research participants and the Primary School directors and teachers, without whom the study would not have been possible.

This work was supported by Universidad Católica de Valencia "San Vicente Martir" [Grant No. 2013/158/002]. The authors' contributions are as follows: AP, VN and LE, conception and design of the study; VN, DC and VV, data acquisition; AP, LE and VN, data analysis and interpretation; VN and AP, drafting of the manuscript; AP, VN, VV, DC and LE, revision of the manuscript; the final version of the manuscript was approved by all the authors.

\section{References}

Alberga, A.S., Sigal, R.J., Goldfield, G., Prud'homme, D., and Kenny, G.P. 2012. Overweight and obese teenagers: why is adolescence a critical period? Pediatr. Obes. 7(4): 261273. doi:10.1111/j.2047-6310.2011.00046.x.

American Diabetes Association. 2015. Standards of medical care in diabetes_2015. Diabetes Care J. Clin. Appl. Res. Educ. 38(1): S8-S16.

Aranceta, J., Pérez, C., Alberdi, G., Varela, G., and Serra-Majem, L. 2015. Controversies about population, clinical or basic research studies related with food, nutrition, 
physical activity and lifestyle. Nutr. Hosp. 31 Suppl 3: 15-21. doi:10.3305/nh.2015.31.sup3.8746.

Ardoy, D.N., Artero, E.G., Ruiz, J.R., Labayen, I., Sjöström, M., Castillo, M.J., et al. 2013. Effects on adolescents' lipid profile of a fitness-enhancing intervention in the school setting; the EDUFIT study. Nutr. Hosp. 28(1): 119-126. doi:10.3305/nh.2013.28.1.6146.

Brisbois, T.D., Farmer, A.P., and McCargar, L.J. 2012. Early markers of adult obesity: a review. Obes. Rev. Off. J. Int. Assoc. Study Obes. 13(4): 347-367. doi:10.1111/j.1467-789X.2011.00965.x.

Busto, R., Amigo, I., Herrero, J., and Fernández, C. 2006. La relación entre la falta de sueño, el ocio sedentario y el sobrepeso infantil. Anál. Modif. Conducta, 32(143). Available from http://www.uhu.es/publicaciones/ojs/index.php/amc/article/view/1930 [accessed 30 April 2017].

Castro-Piñero, J., González-Montesinos, J.L., Keating, X.D., Mora, J., Sjöström, M., and Ruiz, J.R. 2010. Percentile Values for Running Sprint Field Tests in Children Ages 617 Years: Influence of Weight Status. Res. Q. Exerc. Sport, 81(2): 143-151. doi:10.5641/027013610X13088554297035.

de la Cerda, F., and Herrero, C. 2014. Hipertensión arterial en niños y adolescentes. Protoc. Diagn. Ter. Pediatr. 1: 171-189.

Chorlian, D.B., Rangaswamy, M., Manz, N., Wang, J.-C., Dick, D., Almasy, L., et al. 2013. Genetic and neurophysiological correlates of the age of onset of alcohol use disorders in adolescents and young adults. Behav. Genet. 43(5): 386-401. doi:10.1007/s10519013-9604-z.

Cordero, M.J.A., Piñero, A.O., Vilar, N.M., García, J.C.S., Verazaluce, J.J.G., García, I.G., et al. 2014. Programas de actividad física para reducir sobrepeso y obesidad en niños y 
adolescentes. Revisión sistemática. Nutr. Hosp. 30(n04): 727-740. doi:10.3305/nh.2014.30.4.7680.

Currie, C., Zanotti, C., Morgan, A., Currie, D., de Looze, M., Roberts, C., et al. 2012. Social determinants of health and well-being among young people. Health behavior in school-aged children (HBSC) study: International report from the 2009/2010 survey. WHO Regional Office for Europe, Copenhaguen, Denmark.

Dobbins, M., Husson, H., DeCorby, K., and LaRocca, R. 2013. School-based physical activity programs for promoting physical activity and fitness in children and adolescents aged 6 to 18. Cochrane Database Syst. Rev. 28(2). doi:10.1002/14651858.CD007651.pub2.

Drapeau, V., Savard, M., Gallant, A., Nadeau, L., and Gagnon, J. 2016. The Effectiveness of A School-Based Nutrition Intervention on Children's Fruit, Vegetables, and Dairy Product Intake. J. Sch. Health, 86(5): 353-362. doi:10.1111/josh.12385.

Dubois, L., Girard, M., Potvin Kent, M., Farmer, A., and Tatone-Tokuda, F. 2009. Breakfast skipping is associated with differences in meal patterns, macronutrient intakes and overweight among pre-school children. Public Health Nutr. 12(1): 19-28. doi:10.1017/S1368980008001894.

Fiuza-Luces, C., Garatachea, N., Berger, N.A., and Lucia, A. 2013. Exercise is the Real Polypill. Physiology, 28(5): 330-358. doi:10.1152/physiol.00019.2013.

Gálvez, A., Rodríguez, P.L., Rosa, A., García-Cantó, E., Pérez, J.J., Tárraga, M.L., et al. 2014. Nivel de condición física y su relación con el estatus de peso corporal en escolares [physical fitness level and its relationship with body weight status in school children]. Nutr. Hosp. 31(01): 393-400. doi:10.3305/nh.2015.31.1.8074.

García-Artero, E., Ortega, F.B., Ruiz, J.R., Mesa, J.L., Delgado, M., González-Gross, M., et al. 2007. El perfil lipídico-metabólico en los adolescentes está más influido por la 
condición física que por la actividad física (estudio AVENA)*. Rev. Esp. Cardiol. 60(06): 581-588. doi:10.1157/13107114.

Gourlan, M.J., Trouilloud, D.O., and Sarrazin, P.G. 2011. Interventions promoting physical activity among obese populations: a meta-analysis considering global effect, long-term maintenance, physical activity indicators and dose characteristics. Obes. Rev. Off. J. Int. Assoc. Study Obes. 12(7): e633-645. doi:10.1111/j.1467-789X.2011.00874.x.

Guzman, N. 2012. Validación de los cuestionarios de calidad de vida KIDSCREEN y DISABKIDS en niños y adolescentes venezolanos. Universidad de Alicante, Alicante. Available from http://rua.ua.es/dspace/handle/10045/24043 [accessed 5 July 2016].

Institute for Health Metrics and Evaluation (IHME). 2013. The global burden of disease: generating evidence, guiding policy. In IHME. Seattle, WA.

International Sport and Culture Association / Cebr. 2015. The economic cost of physical inactivity in Europe.

Jerdén, L., Burell, G., Stenlund, H., Weinehall, L., and Bergström, E. 2011. Gender differences and predictors of self-rated health development among Swedish adolescents. J. Adolesc. Health Off. Publ. Soc. Adolesc. Med. 48(2): 143-150. doi:10.1016/j.jadohealth.2010.06.005.

Kriemler, S., Meyer, U., Martin, E., van Slujis, E., Andersen, L., and Martin, B. 2011. Effect of school-based interventions on physical activity and fitness in children and adolescents: a review of reviews and systematic update. Br. J. Sports Med. 45(11). doi:10.1136/bjsports-2011-090186.

Lavelle, H., Mackay, D., and Pell, J. 2012. Systematic review and meta-analysis of schoolbased interventions to reduce body mass index. J. Public Health, 34(3): 360-369. 
Lee, I.M., Shiroma, E.J., Lobelo, F., Puska, P., Blair, S.N., and Katzmarzyk, P.T. 2012. Impact of Physical Inactivity on the World's Major Non-Communicable Diseases. Lancet, 380(9838): 219-229. doi:10.1016/S0140-6736(12)61031-9.

Léger, L., and Gadoury, C. 1989. Validity of the $20 \mathrm{~m}$ shuttle run test with $1 \mathrm{~min}$ stages to predict VO2max in adults. Can. J. Sport Sci. J. Can. Sci. Sport, 14(1): 21-26.

Li, L., Zhang, S., Huang, Y., and Chen, K. 2017. Sleep duration and obesity in children: A systematic review and meta-analysis of prospective cohort studies. J. Paediatr. Child Health, 11(2): 140-150. doi:10.1111/jpc.13434.

Llargués, E., Franco, R., Recasens, A., Nadal, A., Vila, M., Pérez, M.J., et al. 2009. Estado ponderal, hábitos alimentarios y de actividad física en escolares de primer curso de educación primaria: estudio AVall. Endocrinol. Nutr. 56(6): 287-292. doi:10.1016/S1575-0922(09)71943-6.

Louie, J.C.Y., Flood, V.M., Hector, D.J., Rangan, A.M., and Gill, T.P. 2011. Dairy consumption and overweight and obesity: a systematic review of prospective cohort studies. Obes. Rev. Off. J. Int. Assoc. Study Obes. 12(7): e582-592. doi:10.1111/j.1467-789X.2011.00881.x.

Luo, B., Yang, Y., Nieman, D.C., Zhang, Y., Wang, J., Wang, R., et al. 2013. A 6-week diet and exercise intervention alters metabolic syndrome risk factors in obese Chinese children aged 11-13 years. J. Sport Health Sci. 2(4): 236-241. doi:10.1016/j.jshs.2013.05.001.

McVeigh, J., and Meiring, R. 2014. Physical Activity and Sedentary Behavior in an Ethnically Diverse Group of South African School Children. J. Sports Sci. Med. 13(2): 371-378. 
Morgen, C.S., and Sørensen, T.I.A. 2014. Obesity: global trends in the prevalence of overweight and obesity. Nat. Rev. Endocrinol. 10(9): 513-514. doi:10.1038/nrendo.2014.124.

Nebot, V., Pablos, A., Elvira, L., Guzmán, J.F., Drehmer, E., and Pablos, C. 2015 a. Validation of Eating Habits Subscale inchildren (SEHAN: Spanish Version) from 10 to 12 year. Nutr. Hosp. 31(04): 1533-1539. doi:10.3305/nh.2015.31.4.8413.

Nebot, V., Pablos, A., Elvira, L., Guzmán, J.F., and Pablos, C. 2015b. Effects of an intervention program (HHP) on the promotion of healthy habits in early adolescence. Nutr. Hosp. 32(06): 2640-2649. doi:10.3305/nh.2015.32.6.9858.

Ng, M., Fleming, T., Robinson, M., Thomson, B., Graetz, N., Margono, C., et al. 2014. Global, regional, and national prevalence of overweight and obesity in children and adults during 1980-2013: a systematic analysis for the Global Burden of Disease Study 2013. The Lancet, 384(9945): 766-781. doi:10.1016/S0140-6736(14)60460-8.

de Onis, M., Onyango, A.W., Borghi, E., Siyam, A., Nishida, C., and Siekmann, J. 2007. Development of a WHO growth reference for school-aged children and adolescents. Bull. World Health Organ. 85(9): 660-667.

Pedersen, B.K., and Saltin, B. 2015. Exercise as medicine - evidence for prescribing exercise as therapy in 26 different chronic diseases. Scand. J. Med. Sci. Sports, 25 Suppl 3: 172. doi:10.1111/sms.12581.

Pérez-Rodrigo, C., and Aranceta, J. 2001. School-based nutrition education: lessons learned and new perspectives. Public Health Nutr. 4(1A): 131-139.

Pomerleau, J., Lock, K., and McKee, M. 2006. The burden of cardiovascular disease and cancer attributable to low fruit and vegetable intake in the European Union: differences between old and new Member States. Public Health Nutr. 9(5): 575-583. doi:10.1079/PHN2005910. 
Rice, B.H., Quann, E.E., and Miller, G.D. 2013. Meeting and exceeding dairy recommendations: effects of dairy consumption on nutrient intakes and risk of chronic disease. Nutr. Rev. 71(4): 209-223. doi:10.1111/nure.12007.

Ruiz, J.R., Castro-Piñero, J., Artero, E.G., Ortega, F.B., Sjöström, M., Suni, J., et al. 2009. Predictive validity of health-related fitness in youth: a systematic review. Br. J. Sports Med. 43(12): 909-923. doi:10.1136/bjsm.2008.056499.

Ruiz, J.R., Cavero-Redondo, I., Ortega, F.B., Welk, G.J., Andersen, L.B., and MartinezVizcaino, V. 2016. Cardiorespiratory fitness cut points to avoid cardiovascular disease risk in children and adolescents; what level of fitness should raise a red flag? A systematic review and meta-analysis. Br. J. Sports Med. 50(23): 1451-1458. doi:10.1136/bjsports-2015-095903.

Sánchez-Cruz, J.-J., Jiménez-Moleón, J.J., Fernández-Quesada, F., and Sánchez, M.J. 2013. Prevalence of child and youth obesity in Spain in 2012. Rev. Esp. Cardiol. 66(5): 371376. doi:10.1016/j.rec.2012.10.012.

Silveira, J.A.C., Taddei, J.A.A.C., Guerra, P.H., and Nobre, M.R.C. 2011. Effectiveness of school-based nutrition education interventions to prevent and reduce excessive weight gain in children and adolescents: a systematic review. J. Pediatr. (Rio J.), 87(5): $382-$ 392. doi:10.2223/JPED.2123.

Steinberg, L., Albert, D., Cauffman, E., Banich, M., Graham, S., and Woolard, J. 2008. Age differences in sensation seeking and impulsivity as indexed by behavior and selfreport: evidence for a dual systems model. Dev. Psychol. 44(6): 1764-1778.

Stewart, A., and Marfell-Jones, M. 2006. International Standards for Anthropometric Assessment. International Society for Advancement of Kinanthropometry, Potchefstroom. 
Szajewska, H., and Ruszczynski, M. 2010. Systematic review demonstrating that breakfast consumption influences body weight outcomes in children and adolescents in Europe. Crit. Rev. Food Sci. Nutr. 50(2): 113-119. doi:10.1080/10408390903467514.

Taheri, S., Lin, L., Austin, D., Young, T., and Mignot, E. 2004. Short sleep duration is associated with reduced leptin, elevated ghrelin, and increased body mass index. PLoS Med. 1(3): e62. doi:10.1371/journal.pmed.0010062.

Tam, W., Keung, V., Lee, A., Lo, K., and Cheung, C. 2014. Chinese translation and validation of a parental feeding style questionnaire for parents of Hong Kong preschoolers. BMC Public Health, 14: 1194. doi:10.1186/1471-2458-14-1194.

Tamnes, C.K., Ostby, Y., Fjell, A.M., Westlye, L.T., Due-Tønnessen, P., and Walhovd, K.B. 2010. Brain maturation in adolescence and young adulthood: regional age-related changes in cortical thickness and white matter volume and microstructure. Cereb. Cortex, 1991 20(3): 534-548. doi:10.1093/cercor/bhp118.

World Health Organization. 2010. Recomendaciones mundiales sobre actividad fisica para la salud. World Health Organization, Suiza. Available from http://apps.who.int/iris/bitstream/10665/44441/1/9789243599977_spa.pdf [accessed 28 July 2016].

Wu, J., Wu, H., Wang, J., Guo, L., Deng, X., and Lu, C. 2015. Associations between Sleep Duration and Overweight/Obesity: Results from 66,817 Chinese Adolescents. Sci. Rep. 16(5): 16686. doi:10.1038/srep16686. 
Table 1. Sample Characteristics of Students who Completed the Program.

\begin{tabular}{|c|c|c|c|c|}
\hline Demographics & $\begin{array}{c}\text { Control } \\
(n=76)\end{array}$ & $\begin{array}{c}\text { Intervention } \\
\quad(\mathrm{n}=\mathbf{8 2})\end{array}$ & $\begin{array}{c}\text { Total } \\
(\mathrm{N}=158)\end{array}$ & $P$ \\
\hline Age, mean (SD) & $10.64(.795)$ & $10.67(.630)$ & $10.66(.712)$ & .819 \\
\hline Gender (female), N (\%) & $41(53.9)$ & $41(50)$ & $82(51.9)$ & 620 \\
\hline Grade (5), N (\%) & $31(40.8)$ & $28(34.1)$ & $59(37.3)$ & .388 \\
\hline Eating at the school canteen, $\mathrm{N}(\%)$ & $34(44.7)$ & $40(48.8)$ & $74(46.8)$ & .611 \\
\hline BMI, N (\%) & & & & .170 \\
\hline Normal weight & $40(52.6)$ & $38(46.3)$ & $78(49.4)$ & \\
\hline Overweight & $20(26.3)$ & $16(19.5)$ & $36(22.8)$ & \\
\hline Obese & $16(21.1)$ & $28(34.1)$ & $44(27.8)$ & \\
\hline
\end{tabular}

No significant differences $(\mathrm{P}<.05)$ were found between the control and the intervention group. N, number of participants; BMI, body mass index 
Table 2. Differences between the groups in post intervention ( 8 month) values, analyzed with ANOVA for Physiological and Anthropometric Variables.

\begin{tabular}{|c|c|c|c|c|c|c|c|c|c|c|}
\hline & \multicolumn{3}{|c|}{ Control $(n=76)$} & \multicolumn{3}{|c|}{ Intervention $(\mathrm{n}=\mathbf{8 2})$} & \multicolumn{4}{|c|}{ Group differences } \\
\hline & Baseline & 8-month & $P$-value & Baseline & 8-month & $P$-value & $\begin{array}{l}\text { Baseline } \\
P \text {-value }\end{array}$ & $\begin{array}{l}\text { 8-month } \\
P \text {-value }\end{array}$ & $\begin{array}{c}\text { Difference }(95 \% \text { CI) } \\
\text { Control vs Intervention }\end{array}$ & $\eta^{2}$ \\
\hline $\mathrm{TC}, \mathrm{mg} / \mathrm{dL}$ & $166.8(18.6)$ & $167.6(18.9)$ & .516 & $168.4(23.9)$ & $163.2(13.1)$ & .074 & .650 & .087 & $-4.42(-9.1$ to .65$)$ & .019 \\
\hline $\mathrm{TG}, \mathrm{mg} / \mathrm{dL}$ & $112.7(52.5)$ & $129.5(78.8)$ & .302 & $117.7(47.1)$ & $99.6(25.1)$ & $.002 *$ & .533 & $.001 *$ & $-29.87(-47.98$ to -11.77$)$ & .064 \\
\hline $\mathrm{BG}, \mathrm{mg} / \mathrm{dL}$ & $62.4(9.1)$ & $75.5(12.3)$ & $<.001 *$ & $59.9(10.4)$ & $70.4(10.5)$ & $<.001 *$ & .109 & $.005^{*}$ & $-5.12(-8.70$ to -1.53$)$ & .049 \\
\hline DBP, $\mathrm{mmHg}$ & $70.6(12.1)$ & $67.3(11.1)$ & $.046 *$ & $73.3(14.2)$ & $67.8(11.5)$ & $<.001 *$ & .202 & .784 & $.49(-3.06$ to 4.05$)$ & - \\
\hline $\mathrm{SBP}, \mathrm{mmHg}$ & $114.3(14.3)$ & $110.9(13.7)$ & .074 & $115.6(16.3)$ & $110.7(15.4)$ & $.031 *$ & .605 & .914 & $-.25(-4.85$ to 4.35$)$ & - \\
\hline $\mathrm{VO}_{2} \max , \mathrm{ml} \cdot \mathrm{kg}^{-1} \cdot \min ^{-1}$ & $43.8(3.9)$ & $42.8(4.3)$ & $<.001 *$ & $43.4(4.3)$ & $44.5(4.9)$ & $<.001 *$ & .523 & $.021 *$ & $1.73(.27$ to -3.19$)$ & .034 \\
\hline BMI, $\mathrm{kg} / \mathrm{m}^{2}$ & $19.6(3.6)$ & $20.3(3.7)$ & $<.001 *$ & $20.8(4.7)$ & $20.9(4.6)$ & .691 & .062 & .400 & $.57(-.76$ to 1.89$)$ & .005 \\
\hline
\end{tabular}

Abbreviation: CT, Total Cholesterol; TG, Triglycerides; BG, Blood Glucose; DBP, Diastolic Blood Pressure; SBP, Systolic Blood Pressure; VO ${ }_{2}$ max, Maximal Oxygen Consumption; BMI, Body Mass Index.

qData are given as mean (SD)

*Indicates a significant change $(\mathrm{p}<.05)$ 
Table 3. Prevalence for the Biochemical Variables, Blood Pressure and BMI According to Level for Both Groups (CG or IG).

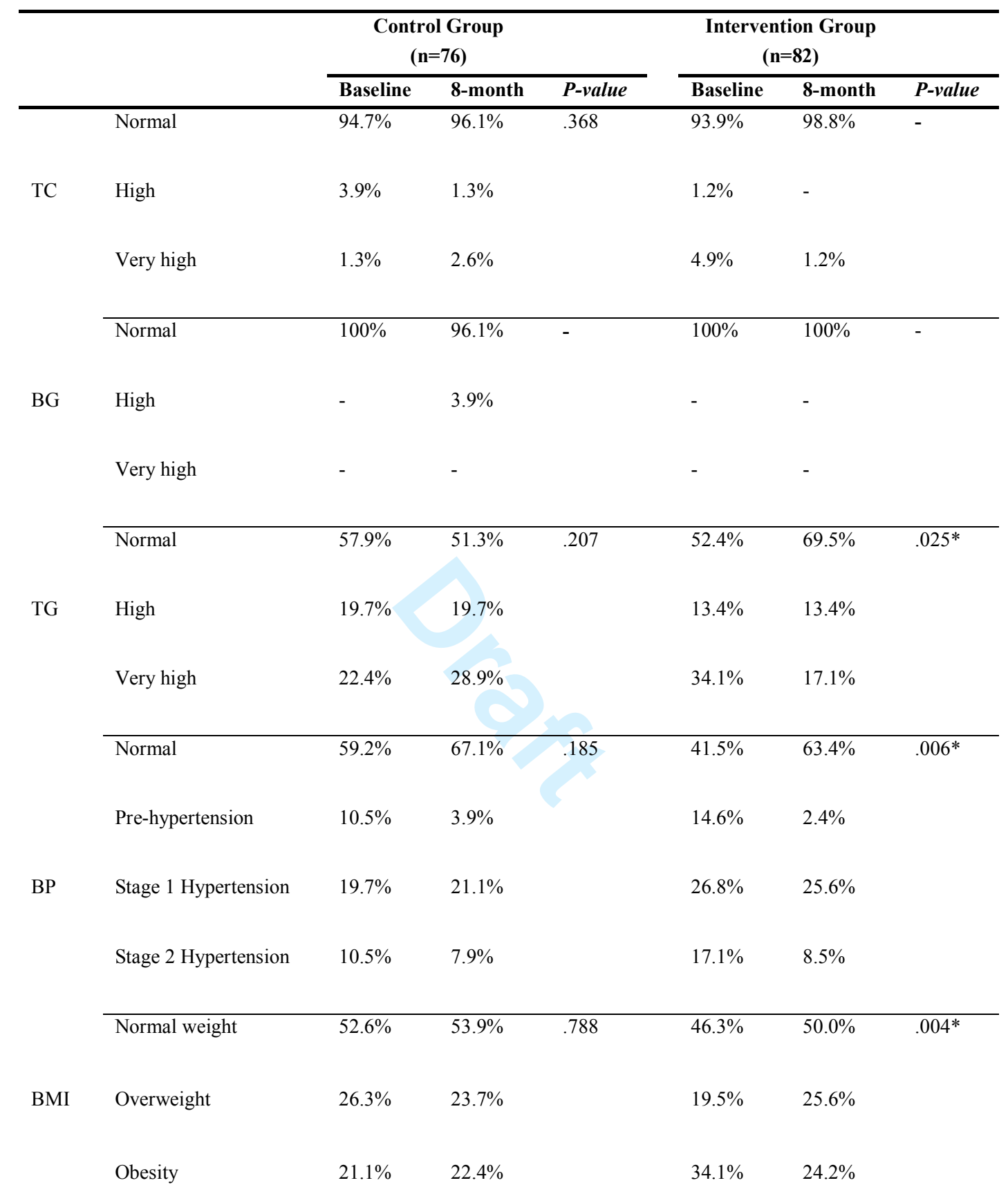

Abbreviation: TC, Total Cholesterol; BG, Blood Glucose; TG, Triglycerides; BP, Blood Pressure; BMI, Body Mass Index.

*Indicates a significant change $(\mathrm{p}<.05)$ from baseline 
Table 4. Differences between the groups in post intervention (8 month) values, analyzed with ANOVA for Health Habit Variables.

\begin{tabular}{|c|c|c|c|c|c|c|c|c|c|c|}
\hline & \multicolumn{3}{|c|}{ Control $(n=76)$} & \multicolumn{3}{|c|}{ Intervention $(\mathrm{n}=\mathbf{8 2})$} & \multicolumn{4}{|c|}{ Group differences } \\
\hline & Baseline & 8-month & $P$-value & Baseline & 8-month & $P$-value & $\begin{array}{c}\text { Baseline } \\
P \text {-value }\end{array}$ & $\begin{array}{l}\text { 8-month } \\
P \text {-value }\end{array}$ & $\begin{array}{c}\text { Difference (95\% CI) } \\
\text { Control vs Intervention }\end{array}$ & $\eta^{2}$ \\
\hline $\mathrm{BR}$, index $^{\dagger}$ & $7.11(5.8)$ & $6.57(5.5)$ & .233 & $7.2(4.2)$ & $8.3(3.1)$ & $.004^{*}$ & .911 & $.014^{*}$ & $1.76(.37$ to 3.16$)$ & .038 \\
\hline $\mathrm{FQ}$, index ${ }^{\dagger}$ & $56.8(9.6)$ & $53.6(10.6)$ & $.012 *$ & $57.4(8.2)$ & $58.6(8.2)$ & .264 & .688 & $.001 *$ & $4.99(2.02$ to 7.96$)$ & .066 \\
\hline $\mathrm{FF}$, index ${ }^{\dagger}$ & $28.9(4.0)$ & $29.1(4.2)$ & .631 & $29.3(4.4)$ & $30(4.3)$ & $.042 *$ & .521 & .171 & $.93(-.41$ to 2.27$)$ & .012 \\
\hline $\mathrm{PA}, \mathrm{min} /$ week & $574.1(365.7)$ & $492.8(367.2)$ & $.016^{*}$ & $436.4(325)$ & $508.5(392)$ & .111 & $.013^{*}$ & .796 & $15.71(-103.95$ to 135.36$)$ & - \\
\hline HS, hours/day & $9.7(.7)$ & $9.4(.7)$ & $.021 *$ & $9.5(.7)$ & $9.5(.7)$ & .484 & .114 & .919 & $-.011(-.22$ to .20$)$ & - \\
\hline ST, hours/day & $2.2(.1)$ & $2.0(.8)$ & .093 & $2.2(.9)$ & $2.1(.7)$ & .386 & .858 & .627 & $.06(-.18$ to .29$)$ & .002 \\
\hline SPH, index ${ }^{\dagger}$ & $2.6(.5)$ & $2.9(.6)$ & $<.001^{*}$ & $2.6(.5)$ & $3(.7)$ & $<.001^{*}$ & .904 & .515 & $.07(-.14$ to .27$)$ & .003 \\
\hline
\end{tabular}

Abbreviation: BR, breakfast; FQ, food quality; FF, food frequency; PA, physical activity; HS, hours of sleep; ST, sedentary time; SPH, self-perceived health.

qData are given as mean (SD)

${ }^{\dagger}$ A higher score indicates a better behavior. FQ index 0-74, $1=$ worst; FF index 0-44, $1=$ worst; SPH index 1-4, $1=$ worst.

*Indicates a significant change $(\mathrm{p}<.05)$ 
